\title{
INVESTIGATIONS ON WEAR MECHANISMS OF PVD COATINGS ON CARBIDES AND SIALONS
}

The paper presents the results on the wear resistance of PVD coatings on cutting inserts made from sintered carbide and sialon ceramics. The exploitative properties of coatings in technological cutting trials were defined in the paper, which also examined the adhesion of coatings to the substrate, the thickness of the coating, and the microhardness. As a result, it was found that isomorphic coating with AlN-h phase of covalent interatomic bonds exhibits much better adhesion to the sialon substrate than isomorphic coating with titanium nitride TiN. These coatings assure the high wear resistance of the coated tools, and the high adhesion combined with the high microhardness and fine-grained structure assure an increase in the exploitative life of the coated tools. In the case of coatings on substrate made from sintered carbide, there was a significant influence on the properties of the tools coated with them as concerns the existence of the diffusion zone between the substrate and the coating.

Keywords: PVD coatings, Carbides, Sialon Tool Ceramics

\section{Introduction}

Due to the constantly increasing requirements for workpieces, tools are subject to ever higher demands, mainly related to the working time of the edge, its hardness, speed and depth of cutting. Currently the pursuit of increased productivity tools involves increasing the thickness of the material for cutting and shortening the time of a single passage. This determines the required properties of those tools, and in particular, but not only, the hardness of the edge. Equally important in the case of coated tools is the adhesion of the coating to the substrate, which results in fatigue and mechanical strength. Adhesion of the coating to the substrate has an influence primarily on the durability. Also important is a decrease in the coefficient of friction, which has a large impact on the processing conditions, because it decreases the treatment temperature and eliminates liquid cooling, which in turn results in an increased risk of corrosion. For this purpose, numerous investigations are conducted to improve the properties of tools [1-10].

Different cutting speeds, feed rates and cutting layer thickness determine the wear on different tools (Fig. 1). Depending on the workpiece, the operation, the tool material and cutting conditions, the complete wear of a tool may include either a single type of wear or a combination of several different types. In the process of the finishing milling, both wear and diffusion dominate, while adhesive or corrosion wear are less important. At low cutting speed, the wear mechanisms on the tools are mainly abrasive and adhesive wear. In general, the wear occurring on cutting tools is dominated by four major types [1-7]:

- adhesive wear,

- abrasive wear,

- diffusion wear,

- corrosive wear.
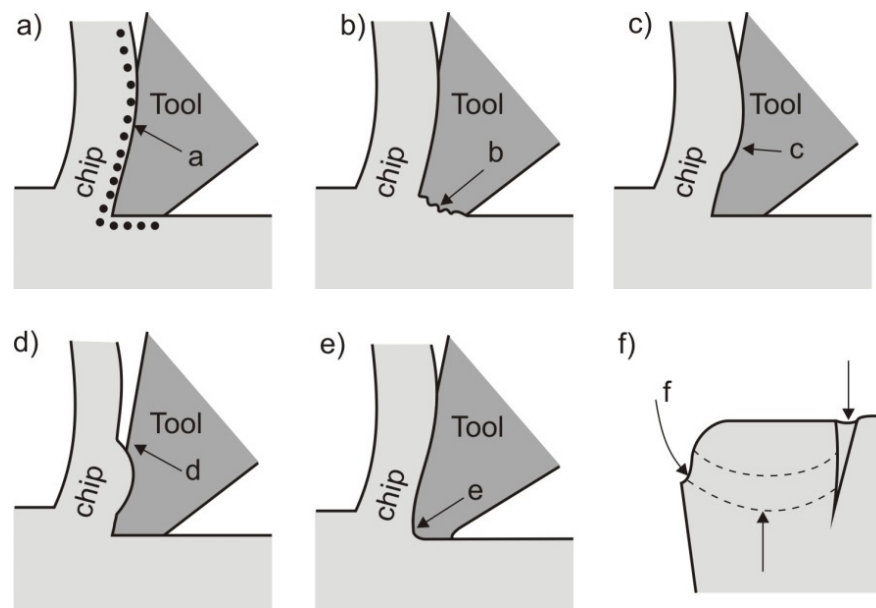

f)

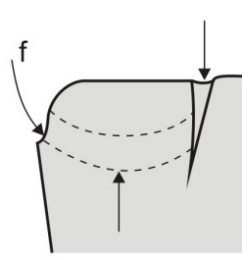

Fig. 1. Diagram of the basic mechanisms of wear of cutting tools: a) abrasive wear; b) adhesive wear; c) diffusion wear; d) wear as a result of plastic deformation of the surface; e) wear as a result of plastic deformation the cutting edges under the action of normal stresses; f) wear by chipping as a result of slip [1] 
Deposition of a coating on the surfaces of cutting tools for high-speed steels, cermet tools and sintered carbides, as well ceramic tools, causes a several fold increase in edge durability by reducing wear on the cutting edges of the tools compared to those that are uncoated or coated only with simple coatings based on simple nitrides or carbide nitrides, by improving the tribological contact conditions in the tool-chip-workpiece contact area, and protecting the tool edge against oxidation and excessive overheating. The rapid development of PVD technology started in the eighties, associated with a wide use of refractory compounds of carbon, nitrogen and boron, in particular with transition metals, as deposition of a thin, hard, anti-wear coating is one of the most important ways to reduce tool wear. Reducing the wear rate and increasing the durability, a low coefficient of thermal conductivity and wear on the effects of high temperature, and in many cases reducing the oxidation and corrosion processes largely determines the use of coatings obtained in the PVD process and, in some cases, the CVD process for coating of tool materials [11-25].

The work is an original contribution to the development of surface engineering, in particular in the field of PVD coatings. The coating-cutting edge system design is based on the selection of the coating material in order to reduce or completely eliminate the dominant mechanism of wear of the edge. The work describes the impact of the coatings' properties, and in particular coating adhesion, on the dominant mechanism of wear on the coatings. It also explains the influence of the chemical and phase composition of coatings on their adhesion to substrate made from sialon ceramics.

The results of the investigation presented in this work can be valuable guidelines for producers of cutting tools with tool ceramics having PVD coatings. In particular, they can facilitate the selection of coating material in the process of covering tool ceramics that are hampered by the dielectric properties of the ceramics.

\section{Materials}

The research was carried out on multi-point inserts made of sintered carbides of WC-Co type and sialon tool ceramics, noncoated and coated with PVD coatings. The inserts were coated using the cathode arc evaporation process (CAE-PVD) with coatings of the type $\mathrm{Ti}(\mathrm{C}, \mathrm{N}),(\mathrm{Ti}, \mathrm{Al}) \mathrm{N},(\mathrm{Al}, \mathrm{Ti}) \mathrm{N}$ and $(\mathrm{Al}, \mathrm{Cr}) \mathrm{N}$.

\section{Methodology}

A scanning electron microscope Zeiss Supra 35 was used to observe both the structure and morphology of the obtained coatings, as well as damage to the coatings resulting from the examination of coating adhesion to the substrate and the cutting trials inserts.

Based on tests in a glow discharge optical spectrometer Leco GDS 850 the concentration changes of the chemical elements of the coating and the concentration changes in the interphase zone between the coating and substrate material were determined.

A transmission electron microscope JEOL JEM 3010 UHL was used to carry out observations of the structure of the thin foils and diffraction analysis.

The phase composition of samples was carried out using the X-ray diffraction method on X'Pert Pro Panalytical apparatus. The grazing incident X-ray diffraction technique (GIXRD) was applied to carry out tests of the phase composition. The tests were carried out for incidence angles of prime beam $\alpha$ equal to $0.5^{\circ}, 1^{\circ}, 2^{\circ}, 3^{\circ}$ and $4^{\circ}$.

The Vickers method with an applied loading of $3 \mathrm{~N}$ was applied to measure the microhardness of the substrates. The microhardness of the investigated coatings was examined using the dynamic Vickers method in the 'load-unload' mode.

Scratch test analysis on the apparatus CSEM Revetest was conducted to determine the adhesion of the coatings to the substrate. The tests were made with the following parameters: load range $0-100 \mathrm{~N}$, load increase rate $(\mathrm{dL} / \mathrm{dt}) 100 \mathrm{~N} / \mathrm{min}$, penetrator's travel speed $(\mathrm{dx} / \mathrm{dt}) 10 \mathrm{~mm} / \mathrm{min}$, acoustic emission detector's sensitivity AE 1 . The critical load $\mathrm{L}_{\mathrm{C}}$, at which coatings' adhesion is lost, was determined basing on the registered values of the acoustic emission AE.

Technological machining trials were carried out in order to categorize the investigated machining inserts according to their usability properties. Based on dry cutting trials, tests were carried out involving the cutting ability of inserts from sintered carbides and sialon ceramics coated and non-coated with PVD and CVD coatings.

Based on the measurements of the width of the wear band on the tool flank, the durability of the investigated inserts was determined. When the assumed wear criterion for after-machining of $\mathrm{VB}=0.2 \mathrm{~mm}$ was exceeded, the machining trials were stopped.

\section{Results and discussion}

The most important properties of the investigated coatings are presented in Table 1. Based on the observation in the scanning electron microscope, defects were identified in the coatings which occurred while doing the research on the adhesion using the scratch method, and these are presented in Fig. 2. As a result of investigations, it was found that there are four dominant types of damage mechanism which are accompanied to a lesser degree by other phenomena. One-sided and two-sided delamination, which principally involves the coating obtained on the substrates from sintered carbides of the type (Al,Ti)N (Fig. 2a), but also the coating $(\mathrm{Al}, \mathrm{Cr}) \mathrm{N}$ obtained on sialon ceramics, is the first basic mechanism of damage to coatings observed after exceeding the critical load. Total delamination, which involves coating of the type $\mathrm{Ti}(\mathrm{C}, \mathrm{N})$ obtained on the substrate from sintered carbides (Fig. 2b), is the second dominant damage mechanism. Initially, just after exceeding the critical load, two-sided delamination takes place but, with increasing load, this turns into total delamination. We also found in all the coatings obtained on the substrate 
TABLE 1

Characteristics of the investigated PVD coatings

\begin{tabular}{|c|c|c|c|c|c|}
\hline Coatings & Substrate & Thickness of coating, $\mu \mathrm{m}$ & Microhardness, HV0.5 & Critical load $\mathrm{L}_{\mathrm{c}}, \mathrm{N}$ & Tool life, min. \\
\hline uncoated & \multirow{5}{*}{$\begin{array}{l}\text { Sintered } \\
\text { carbides }\end{array}$} & - & 1826 & - & 2 \\
\hline $\mathrm{Ti}(\mathrm{C}, \mathrm{N})$ & & 2.1 & 3101 & 77 & 53 \\
\hline$(\mathrm{Ti}, \mathrm{Al}) \mathrm{N}$ & & 3.5 & 3327 & 109 & 60 \\
\hline$(\mathrm{Al}, \mathrm{Ti}) \mathrm{N}$ & & 2.5 & 3301 & 100 & 55 \\
\hline$(\mathrm{Al}, \mathrm{Cr}) \mathrm{N}$ & & 3.8 & 2867 & 96 & 45 \\
\hline uncoated & \multirow{5}{*}{$\begin{array}{l}\text { Sialon tool } \\
\text { ceramics }\end{array}$} & - & 2035 & - & 11 \\
\hline Ti(C,N) & & 1.8 & 2843 & 26 & 9 \\
\hline$(\mathrm{Ti}, \mathrm{Al}) \mathrm{N}$ & & 5.0 & 2961 & 21 & 10 \\
\hline$(\mathrm{Al}, \mathrm{Ti}) \mathrm{N}$ & & 3.0 & 3600 & 112 & 72 \\
\hline$(\mathrm{Al}, \mathrm{Cr}) \mathrm{N}$ & & 4.8 & 2230 & 53 & 50 \\
\hline
\end{tabular}

from sintered carbides that inside the scratch the defects were affected by tension as well as one- and two-sided chipping along the borders of the scratch. In the case of coating obtained on sialon ceramics of the type (Al,Ti)N, and also the coating ( $\mathrm{Ti}, \mathrm{Al})$ $\mathrm{N}$ obtained on sintered carbides, another damage mechanism was found - abrasion which was accompanied by cohesive fractures of the coatings and slight chipping and flaking. It was found also that in the case of $(\mathrm{Al}, \mathrm{Ti}) \mathrm{N}$ coating on the sialon substrate (Fig. $2 \mathrm{~d}$ ), even with the maximum load of $200 \mathrm{~N}$, the coating was not ruptured, and there were only a few cohesive defects and slight chipping. In the $(\mathrm{Ti}, \mathrm{Al}) \mathrm{N}$ and $\mathrm{Ti}(\mathrm{C}, \mathrm{N})$ coatings obtained on the sialon ceramics, vast chipping and flaking, which occurred immediately after exceeding the critical load (Fig. 2e,f), was observed as the fourth damage mechanism.

On the basis of technological trials of cutting grey cast iron using cemented carbide inserts, it was found that the tested coatings increase the wear resistance of inserts, as manifested by lengthening of their tool life (Table 1). In the case of sialon cutting inserts, it was found that only the $(\mathrm{Al}, \mathrm{Ti}) \mathrm{N}$ and $(\mathrm{Al}, \mathrm{Cr})$ $\mathrm{N}$ coatings have the effect of increasing tool life (Table 1). In each case, the tests were repeated several times; however, the coatings of $\mathrm{Ti}(\mathrm{C}, \mathrm{N})$ and $(\mathrm{Ti}, \mathrm{Al}) \mathrm{N}$ on sialon substrate were rap-
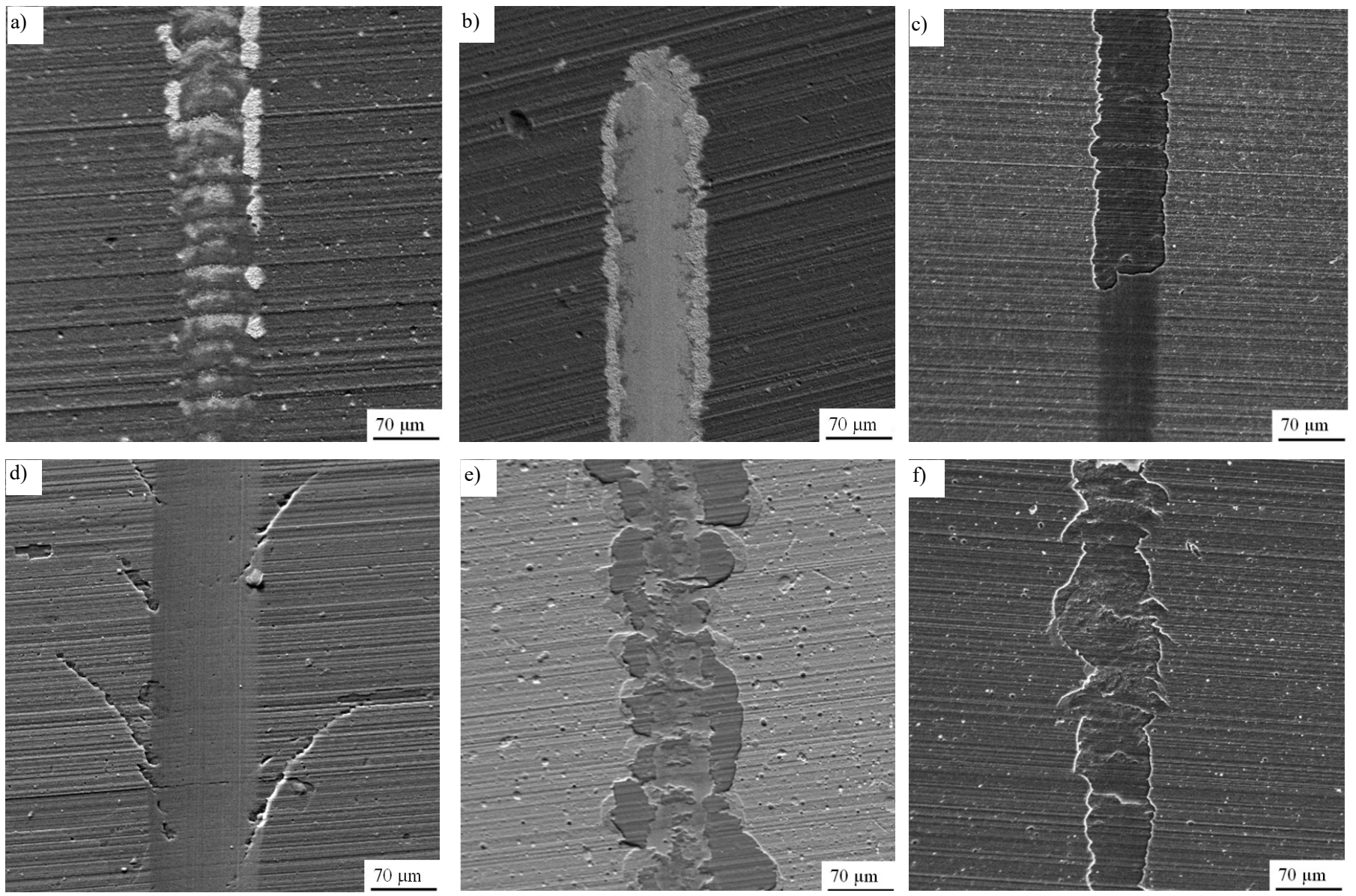

Fig. 2. Characteristic failure obtained by scratch test: a) (Al,Ti)N coating on sintered carbides; b) Ti(C,N) coating on sintered carbides; c) (Al,Cr)N coating on sialon substrate; d) (Al,Ti)N coating on sialon substrate; e) Ti(C,N) coating on sialon substrate; f) (Ti, Al) N coating on sialon substrate 
idly degraded.

From the scanning electron microscope materialographic observations of the effect of the investigated multi-point inserts, it was demonstrated that the wear on tools subjected to machining trials is the result of abrasive and adhesive mechanisms (Fig. 3a). We found a build-up of the machined material on the tool flank, in particular on the cutting edges on the sintered carbides with and without coatings. After 9 minutes of machining (Fig. 3b), we found extensive chipping of the Ti(C,N) coating on the ceramic substrate.

On the basis of X-ray diffraction analysis (Fig. 4) and investigations of thin foil in the transmission electron microscope (Fig. 5), it was found that the coatings of $\mathrm{Ti}(\mathrm{C}, \mathrm{N})$ and $(\mathrm{Ti}, \mathrm{Al})$ $\mathrm{N}$ contain an isomorphic phase with titanium nitride TiN, while the $(\mathrm{Al}, \mathrm{Ti}) \mathrm{N}$ and $(\mathrm{Al}, \mathrm{Cr}) \mathrm{N}$ coatings are characterized by an isomorphic structure with an aluminium nitride AlN of hexagonal lattice.

The presence of appropriate elements in the investigated gradient layers was confirmed during investigation of chemical composition performed on the glow discharge optical spectrometer GDOES. Changes in the atomic concentration of the components of the coatings and the substrate material are presented in Figure 6. The character of the changes in concentration of the elements which form the coatings indicates their gradient structure. It was demonstrated from the GDOES analysis that in the contact zone, from the surface of the coatings, there is a rise in the concentration of the elements that are components of the substrate, with a simultaneous decrease of the concentration of those elements which are components of the coating. As suggested by the authors of earlier works [15-25], this may be due to the presence of a transit zone of a diffusive character between the substrate material and the coating, although we cannot rule out the possibility of simultaneous non-homogeneous evaporation of the material from the surface of the samples during the glow discharge spectrometer tests.

\section{Summary}

Production technologies and the application of surface layers are well established and are regarded as basic knowledge in the field of materials engineering. A lot of research centers are working on surface engineering worldwide, applying all possible means to fathom and describe the phenomena taking place on the surface of solids. Such a situation motivates scientists to undertake challenging research work aiming to increase the operating
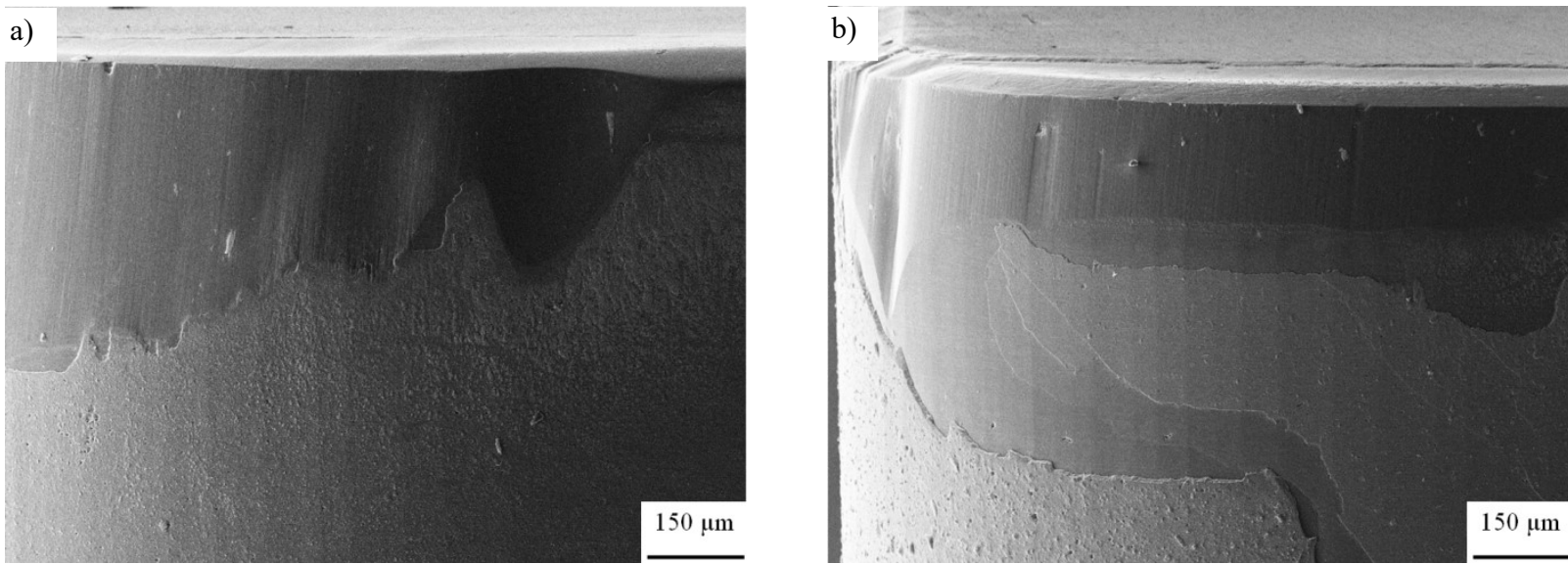

Fig. 3. Characteristic wear of tool flank of sialon tool ceramics inserts with: a) (Al,Ti)N coating; b) Ti(C,)N coating
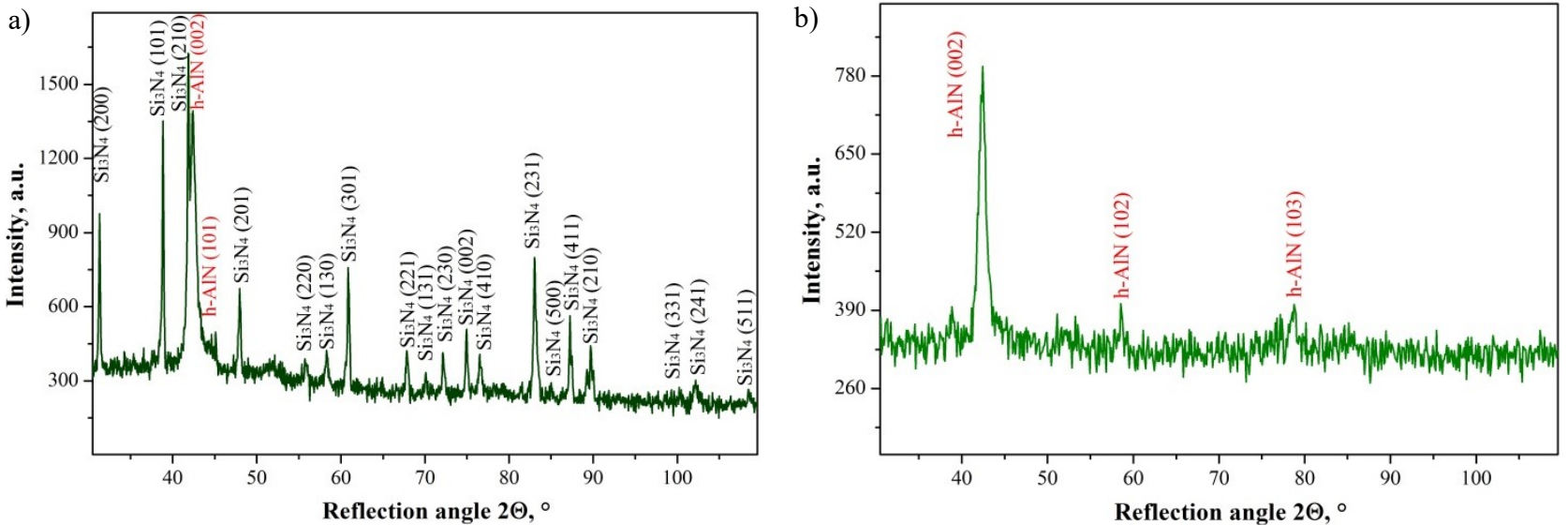

Fig. 4. X-ray diffraction pattern of (Al,Cr)N coating deposited on the sialon ceramics substrate obtained by: a) Bragg-Brentano method; b) GIXRD method $\left(\alpha=4^{\circ}\right)[5]$ 

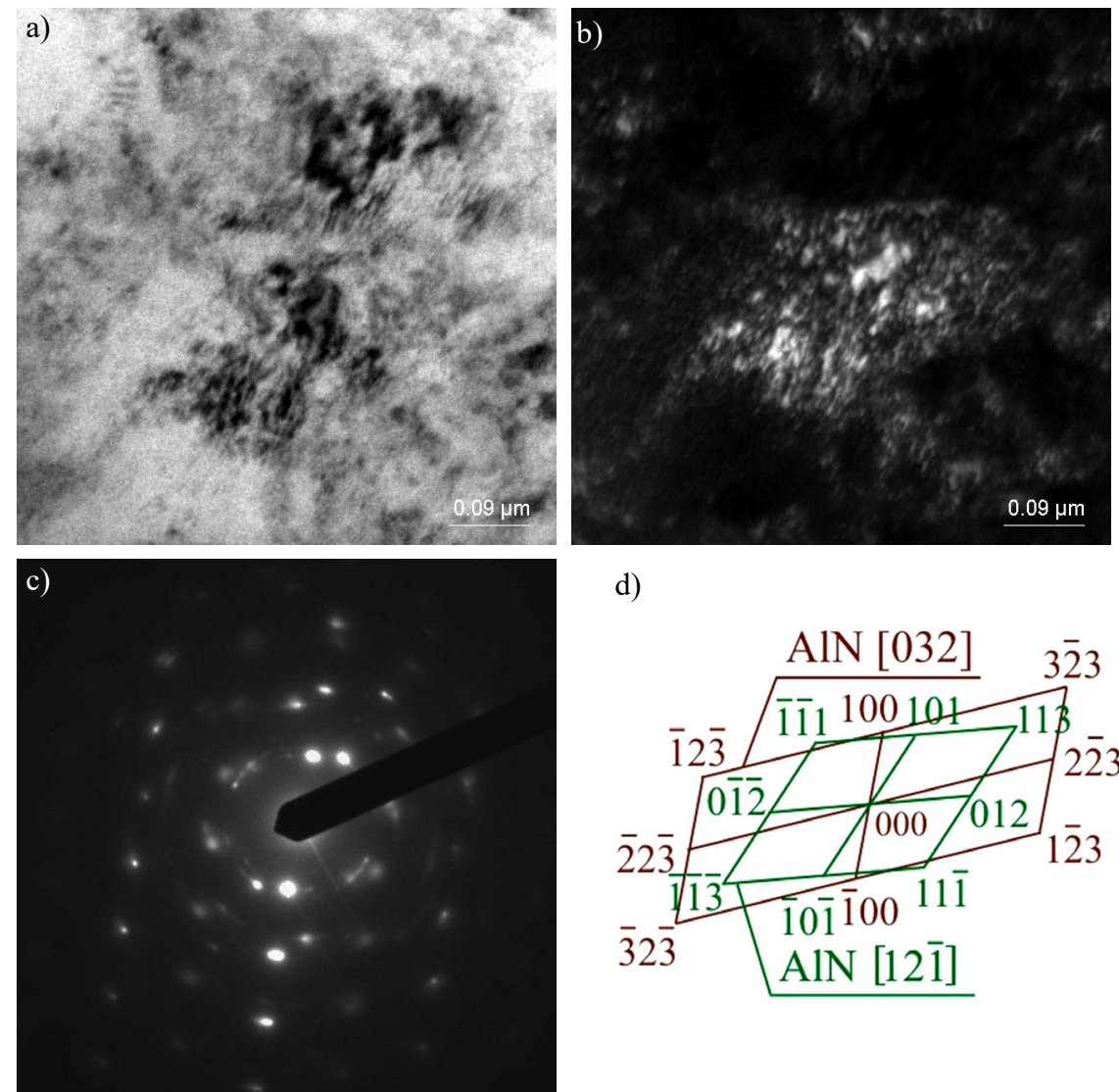

d)

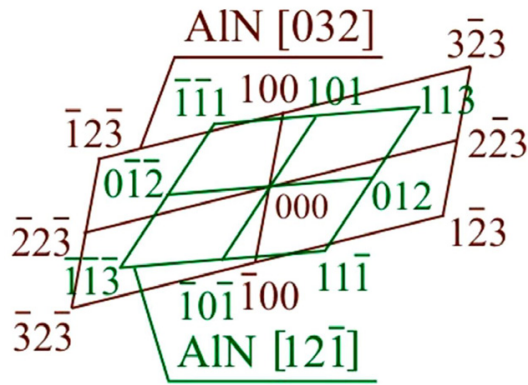

Fig. 5. Structure of (Al,Ti)N coating: a) bright field; b) dark field from -100 reflex; c) diffraction pattern from area b, and d) solution of the diffraction pattern [5]
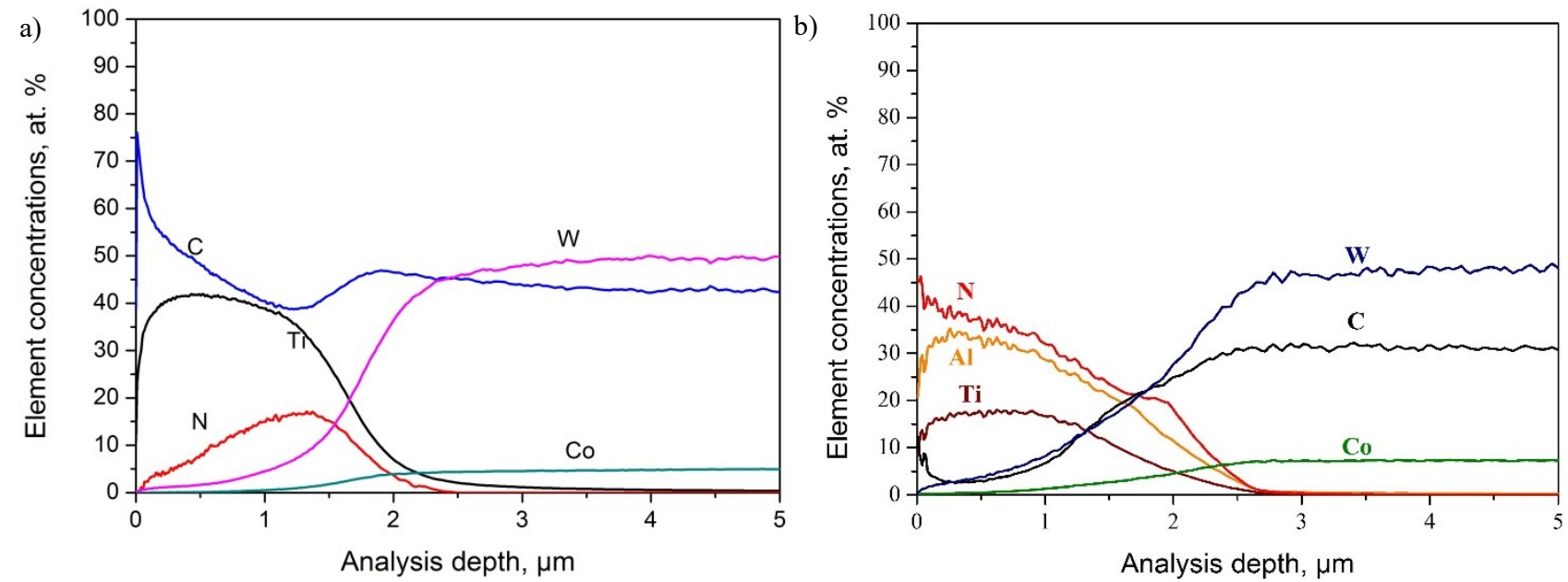

Fig. 6. Changes of constituent concentration of the sintered carbides substrate material and: a) Ti(C,N) coating [5]; b) (Al,Ti)N coating

durability of surface layers, and, in consequence, the durability of the product. In order to reduce or totally eliminate the dominant mechanism of cutting edge wear, the design process of the coating-cutting edge system implies an appropriate selection of coating material. The coating should satisfy various requirements to ensure suitable protection of the tool during the machining process, as has been confirmed by numerous research investigations.

The critical load Lc [N] depends on the proper selection of coating material (chemical composition, phase composition) (Table 1), as determined in the scratch test, this being to a large degree the measure of coating adhesion to the substrate. This relation is particularly relevant with respect to PVD coatings on substrates made of sialon ceramics.

The coatings containing the AlN phase are characterized by very good adhesion to the substrate $\mathrm{Lc}=53 \div 112 \mathrm{~N}$, and the coatings in which only isomorphic phases with TiN are present have poor adhesion to the sialon substrate $\mathrm{Lc}=21 \div 26 \mathrm{~N}$. In the coatings containing isomorphic phases with titanium nitride TiN there are metallic bonds, which result in low adhesion of these coatings to the substrate of any different bond, so we must remember that 
sialons belong to covalence ceramics. There are covalence bonds analogous to the ceramic substrate, which yield good adhesion of these coatings to the substrate in the case of coatings containing AlN phase of the hexagonal lattice. We can understand that the type of interatomic bonds present in the material of the substrate and coating has a great influence on the adhesion of the coatings to the substrate. The adhesion of the coating to substrates made from sintered carbides is conditioned, apart from adhesion, by a slight diffusive displacement of the elements in the contact zone, which is due to the implantation of high energy ions falling on the negatively polarized substrates. As demonstrated by the results of the investigation with the glow discharge optical spectrometer GDOES, high energy ions falling on the polarized substrate bring about various phenomena, including local temperature rise, acceleration of chemisorption, intensification of surface diffusion and diffusion into the substrate. Also slight ion penetration may occur (about several $\mathrm{nm}$ down), as well as partial sputtering of the atoms of the deposited coating.

The defect mechanism of the tested coatings largely depends on their adherence to the substrate, because the coatings that reveal the highest adhesion, high hardness and fine-grained structure are subject to major damage as a result of abrasion both during the scratch test and in the grey cast iron rolling test, while coatings that reveal inferior properties, especially lower critical loads, being a measure of adhesion to the substrate, are subject to cracking, peeling and delimitation.

\section{Conclusions}

- $\quad$ PVD coatings show good adhesion to the substrate from cemented carbides which is characterized by the adhesivediffusion mechanism of adhesion, which is caused by diffuse displaced elements in the transient zone to the coating-substrate; in the case of PVD coatings, this is the result of the implantation of high-energy ions falling on the negatively polarized substrate.

- Good adhesion to sialon ceramics is shown by PVD coatings containing AlN phase in a hexagonal network with covalent bonds of the same type as the ceramic substrate.

- The damage mechanism of the investigated coatings depends largely on their adhesion to the substrate. Coatings showing the highest adhesion, high hardness and also a fine-grained structure were destroyed as a result of abrasion during the investigation, from both the scratch test and the attempted rolling trial of grey cast iron. However, coatings with inferior properties, and in particular the worst adhesion to the substrate, suffered from cracking, flaking and delamination.

\section{Acknowledgements}

This work was supported by the Ministry of Science and Higher Education of Poland as the statutory financial grant of the Faculty of Mechanical Engineering, Silesian University of Technology.

\section{REFERENCES}

[1] L.A. Dobrzański, Engineering materials and materials designing. Fundamentals of materials science and metallurgy. Gliwice-Warsaw, WNT. (2006).

[2] S. Ekinović, Obrada rezanjem. Zenica, BiH. (2001).

[3] M. Staszuk, D. Pakuła, T. Tański, Mater. Tehnol. 50 (5), 755-759 (2016).

[4] M. Basiaga, W. Walke, M. Staszuk, W. Kajzer, A. Kajzer, K. Nowińska, Arch. Civ. Mech. Eng. 17, 32-42 (2017).

[5] L.A. Dobrzański, D. Pakuła, Mater. Sci. Forum 513, 119-133 (2006).

[6] L.A. Dobrzański, K. Gołombek, Journal of Materials Processing Technology 164, 2005, 805-810.

[7] T. Liu, C. Dong, S. Wu, K. Tang, J. Wang, J. Jia, Surf. Coat. Tech. 201, 6737-6741 (2007).

[8] M. Bonek, A. Śliwa, J. Mikuła, Appl. Surf. Sci. 388, 174-179 (2016)

[9] A. Śliwa, W. Kwaśny, M. Sroka, R. Dziwis, Metalurgija 56, 422424 (2017)

[10] M. Krupiński, B. Krupińska, K. Labisz, Z. Rdzawski, W. Borek, J. Therm. Anal. Calorim. 118/2, 1361-1367 (2014).

[11] A. Zieliński, G. Golański, M. Sroka, Mat. Sci. Eng. A 682, 664672 (2017).

[12] A. Drygała, L.A. Dobrzański, M. Szindler, M.M. Szindler, M. Prokopiuk vel Prokopowicz, E. Jonda, Int. J. Hydrogen. Energ. 41 (18), 2016, 7563-7567.

[13] Y. Birol, B. Yuksel, Surf. Coat. Tech. 207, 461-466 (2012).

[14] G.G. Fuentes, E. Almandoz, R. Pierrugues, R. Martínez, R.J. Rodríguez, J. Caro, M. Vilaseca, Surf. Coat. Tech. 205, 1368-1373 (2010).

[15] M. Pancielejko, W. Precht, J. Mater. Process Tech. 157-158, 394298 (2004).

[16] A. Czyżniewski, W. Gulbiński, G. Radnóczi, M. Szerencsi, M. Pancielejko, Surf. Coat. Tech. 205, 4471-4479 (2011).

[17] J.A. Thornton, Journal of Vacuum Science and Technology A4 (6), 3059-3065 (1986).

[18] M. Odén, J. Almer, G. Hakansson, M. Olsson, Thin Solid Films 377-378, 407-412 (2000).

[19] E. Broszeit, C. Friedrich, G. Berg, Surf. Coat. Techn. 115, 9-16 (1999).

[20] P. Bílek, P. Jurči, M. Hudáková, M. Pašák, M. Kusý, J. Bohovičová, Appl. Surf. Sci. 307, 13-19 (2014).

[21] E. Torres, D. Ugues, Z. Brytan, M. Perucca, J. Phys. D. Appl. Phys. 42 (10), (2009).

[22] G.-an. Cheng, D.-yan. Han, C.-lin. Liang, X.-ling. Wu, R.-ting. Zheng, Surf. Coat. Tech. 228, S328-S330 (2013).

[23] H. Shang, J. Li, T. Shao, Appl. Surf. Sci. 310, 317-320 (2014).

[24] J. Zhang, H. Yang, Q.-long. Zhang, S. Dong, J.K. Luo, Appl. Surf. Sci. 282, 390-395 (2013).

[25] V. Subramanian, T. Bakhishev, D. Redinger, S.K. Volkman, J. Disp. Technol. 5/12 525-530 (2009). 